LA W REN CE LIVERMORE N A TIO N A L LABORATORY
Methyl lodide Fumigation of
Bacillus Anthracis Spores

M. Sutton, S. R. Kane, J. R. Wollard

June 28, 2012 
This document was prepared as an account of work sponsored by an agency of the United States government. Neither the United States government nor Lawrence Livermore National Security, LLC, nor any of their employees makes any warranty, expressed or implied, or assumes any legal liability or responsibility for the accuracy, completeness, or usefulness of any information, apparatus, product, or process disclosed, or represents that its use would not infringe privately owned rights. Reference herein to any specific commercial product, process, or service by trade name, trademark, manufacturer, or otherwise does not necessarily constitute or imply its endorsement, recommendation, or favoring by the United States government or Lawrence Livermore National Security, LLC. The views and opinions of authors expressed herein do not necessarily state or reflect those of the United States government or Lawrence Livermore National Security, LLC, and shall not be used for advertising or product endorsement purposes.

This work performed under the auspices of the U.S. Department of Energy by Lawrence Livermore National Laboratory under Contract DE-AC52-07NA27344. 


\title{
Methyl Iodide Fumigation of Bacillus Anthracis Spores
}

\author{
Mark Sutton*, Staci Kane, Jessica Wollard \\ Lawrence Livermore National Laboratory, Livermore, CA 94550 \\ * Corresponding author: sutton18@llnl.gov, (925) 424-2137
}

\begin{abstract}
Fumigation techniques such as chlorine dioxide, vaporous hydrogen peroxide and paraformaldehyde used to decontaminate items, rooms and buildings following contamination with Bacillus anthracis spores are often incompatible with materials. Alternative fumigation with methyl bromide is subject to strict international regulation and requires a crisis exemption from the EPA. Methyl iodide fumigation offers excellent efficacy at both room temperature and elevated temperature. Bacillus anthracis Sterne spores applied to stainless steel were subjected to methyl iodide fumigation at room temperature and at $55^{\circ} \mathrm{C}$. Additionally, spore fumigation on concrete was performed at $55^{\circ} \mathrm{C}$. Efficacy was measured on a log-scale with a 6log reduction in colony forming units being considered successful. Efficacies greater than 6 orders of magnitude were obtained after just 1 hour at $55^{\circ} \mathrm{C}$ and after 12 hours at room temperature for stainless steel samples. No detrimental effects were observed on glassware or PTFE 0-rings. Additional studies should be directed towards assessing the effect of methyl iodide on sensitive or valuable materials such as electronic equipment, fabric, artwork and documents.
\end{abstract}

\section{Introduction}

Following the Amerithrax attacks in 2001 that contaminated a variety of federal, postal and privately owned buildings in Washington DC, New York, New Jersey and Florida with resilient Bacillus anthracis spores (B. anthracis, anthrax), three gases were used to fumigate facilities - chlorine dioxide gas, vaporous hydrogen peroxide and paraformaldehyde [Canter 2005]. Chlorine dioxide gas $\left(\mathrm{ClO}_{2}\right)$ penetrates into porous surfaces [EPA 2005], but reacts with a wide range of materials [NRC 2005] and is known to cause corrosion of some metals including aluminum, iron and copper found in plumbing and electrical equipment [EPA 1999, Canter 2010]. Vaporous hydrogen peroxide $\left(\mathrm{H}_{2} \mathrm{O}_{2}, V H P\right)$ penetrates poorly into porous surfaces, may react with organics [EPA 2005] and is known to cause corrosion of some metals including those important to plumbing and electrical infrastructure [EPA 1999]. Paraformaldehyde ( $P F A$, nominally $\mathrm{OH}\left(\mathrm{CH}_{2} \mathrm{O}\right)_{n} \mathrm{H}$ where $\mathrm{n}=8$ to 100 ) highly penetrates porous materials, is relatively unreactive with most materials. However, PFA gas does react with oxidizers and some organics [CDC 2005], and is a probable human carcinogen [DHHS 2005]. 
Methyl bromide $\left(\mathrm{CH}_{3} \mathrm{Br}, \mathrm{MeBr}\right)$ has been shown to be effective in the fumigation of insect and fungus infestations and has been used experimentally for the fumigation of B. anthracis spores [Kolb 1950, EPA 2005, Corsi 2007, Juergensmeyer 2007]. Methyl bromide highly penetrates into porous surfaces and does not typically react with organics, making it an attractive method for the fumigation of buildings and agricultural areas. Methyl bromide reacts with aluminum, rubber and sulfurcontaining articles, is a neurotoxin and an animal carcinogen (although not proven in humans) [DHHS 2005]. Methyl bromide has been widely used in agricultural fumigation of pests and fungus. However, $\mathrm{MeBr}$ is subject to the Montreal Protocol on Substances that Deplete the Ozone Layer and the EPA Clean Air Act (CAA). Today (as of 2012), use of MeBr in an emergency (such as a wide area biological agent release) requires EPA crisis exception, and alternatives for fumigation are sought.

Methyl iodide $\left(\mathrm{CH}_{3} \mathrm{I}\right.$, iodomethane, $\left.\mathrm{Me}\right)$ is a commercially available alternative to $\mathrm{MeBr}$ fumigation [Ohr et al. 1998] and is a registered pesticide in several countries around the world with fungicide, herbicide, insecticide, nematicide, and soil disinfectant properties similar to $\mathrm{MeBr}$. The boiling point of $\mathrm{MeI}$ is $42.4^{\circ} \mathrm{C}$ and the liquid density is $2.28 \mathrm{~g} / \mathrm{cm}^{3}$ at $20^{\circ} \mathrm{C}$ [CRC 2011]. The compound has restrictions on both the shipment volume and method (no air transport). MeI is not subject to the Montreal Protocol, and as such an exemption permit would not be required from EPA. In fact, the EPA found that:

\begin{abstract}
Once volatilized, iodomethane degrades rapidly in the lower atmosphere via direct photolysis and lasts in the atmosphere less than twelve days, as compared with two years for methyl bromide. Therefore, iodomethane is unlikely to the reach upper atmosphere to have an impact upon the ozone layer. However, global uncertainty on volatilization rates, residence time in soil, photolytic degradation of iodomethane, and the removal of iodine radicals from the troposphere means that the possibility of detrimental effects of iodomethane on ozone layer and a contribution to global warming cannot be excluded entirely [EPA 2007]
\end{abstract}

Therefore, researchers at LLNL proposed using methyl iodide as an alternative to $\mathrm{ClO}_{2}$, VHP, PFA and $\mathrm{MeBr}$ in the fumigation of $\mathrm{B}$. anthracis spores, with experiments to characterize the efficacy of MeI in the neutralization of B. anthracis spores. The objectives of this scoping study were to determine if a 6-log kill (reduction of viable colony-forming units, CFUs by six orders of magnitude) could be achieved using MeI fumigation and to determine the effects of concentration-time-temperature properties on the efficacy. Experiments were performed using the B. anthracis Sterne strain $(34 \mathrm{~F} 2)$ naturally missing the pXO2 plasmid responsible for the layer of polysaccharides outside of the cell wall that protects the bacteria against phagocytosis [CDC 2009]. Experiments were performed on both non-porous (stainless steel) and porous (concrete) surfaces at elevated and room temperatures corresponding to above and below the boiling point of methyl iodide. 


\section{Materials}

Methyl iodide (99\% stabilized with copper or silver, Alfa Aesar purchased from VWR Scientific, CAS 74-88-1, $141.97 \mathrm{~g} / \mathrm{mol}$ ) was stored in an amber glass bottle wrapped in aluminum foil.

Biological indicator ribbons: 304 stainless steel ribbon containing $3 \times 10^{6} \mathrm{~B}$. anthracis Sterne spores (Yakibou Inc., Apex NC). Additionally, a solution of B. anthracis Sterne ( $25 \mu \mathrm{l}$ of a $4 \times 10^{7}$ spore solution) was used to spike concrete coupons at $1 \times 10^{6}$ spores/coupon.

Concrete coupons (EPA) were cut with a diamond-blade wet saw and allowed to dry before use.

Pressure-rated glassware (heavy-walled borosilicate glass, 48ml and $100 \mathrm{ml}$, Ace Glass, Vineland NJ) was used to contain methyl iodide gas during fumigation. Vessels were sealed with accompanying PTFE screw caps and front-seal FETFE 0rings (\#15 and \#36, Ace Glass). PTFE stirrer rods (5 mm diameter, Ace Glass) were cut to size and the stirrer pin was repositioned approximately $2 \mathrm{~cm}$ from the bottom of the rod using a drill press to adequately seat a PTFE disc ( $15 \mathrm{~mm}$ diameter) on which ribbons could be placed in the vapor phase. An alternative sample holder was developed using fishing line (Red Lightnin' premium monofilament, 0.008 " diameter CL4F, Cajun Line, Tulsa OK).

\section{Methods}

\section{Methyl Iodide Fumigation:}

Initially, dry-run experiments were performed to assess the evaporation, pressure and condensation processes with increasing temperature in the absence of B. anthracis Sterne spores, largely to satisfy environmental, safety and health concerns. Methyl iodide ( 5 to $20 \mathrm{ml}$ ) was placed in pressure-rated glassware (48 and $100 \mathrm{ml}$, Ace Glass) fitted with a pressure gauge (0 to $160 \mathrm{psi}$, Ace Glass). The pressure vessel was lowered into a 5-liter digital water bath (VWR) such that the water was level with the bottom of the screw cap (minimizing condensation of methyl iodide at the top of the vessel). A NIST-traceable digital thermometer ( -50 to $300^{\circ} \mathrm{C}, \mathrm{VWR}$ ) was used to verify the water temperature and provide an alarm against over heating. Once the desired heating time was reached, the vessel was removed from the water bath and methyl iodide condensation on the walls of the vessel was observed as both the temperature and pressure inside the vessel dropped to ambient.

The vapor pressure of methyl iodide was calculated from data in Lorez et al. (1976), which states that: 


$$
\log _{10} P(m m)=\frac{1475}{T}+7.56
$$

where $P(\mathrm{~mm})$ is the vapor pressure in $\mathrm{mmHg}, T$ is the temperature in Kelvin. The vapor pressure (psi) of methyl iodide from 0 to $55^{\circ} \mathrm{C}$ is plotted in Figure 1 .

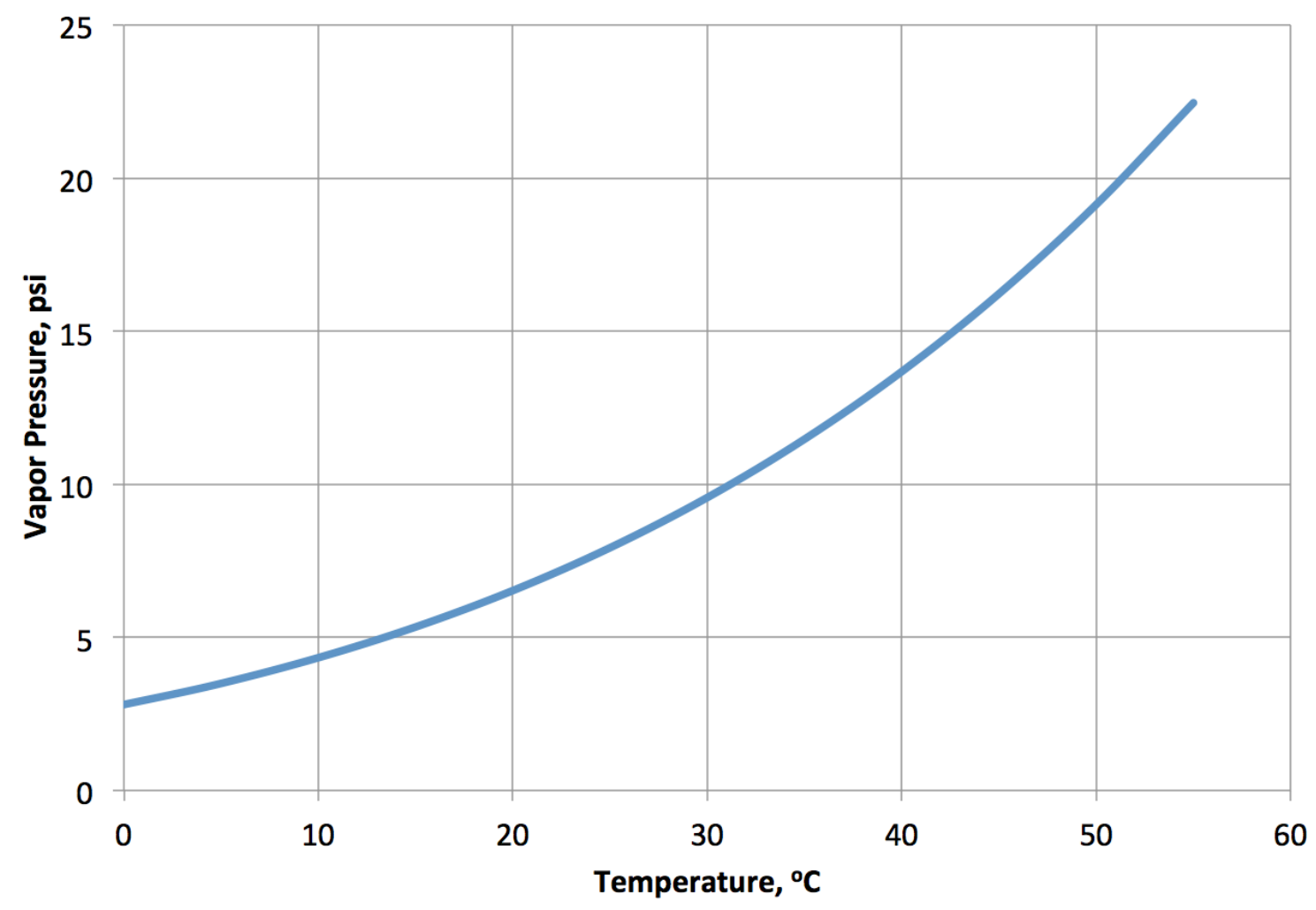

Figure 1. Vapor pressure of methyl iodide versus temperature

The corresponding concentration of MeI in the gas phase was calculated using

$$
P V=n R T
$$

where $P$ is the vapor pressure of methyl iodide (Pascals), $V$ is the volume of gas above the methyl iodide liquid in the pressure-vessel, $n$ is the number of moles of methyl iodide in the gas phase, $R$ is the molar gas constant $\left(8.314 \mathrm{~m}^{3} . \mathrm{Pa} / \mathrm{K} . \mathrm{mol}\right)$ and $T$ is the temperature (Kelvin). The number of moles of methyl iodide in the gas phase was then converted to a mass (mg) per volume (l) using the molar mass of methyl iodide $(141.9 \mathrm{~g} / \mathrm{mol})$ and the headspace volume above the liquid in the pressure vessel. The theoretical concentration of methyl iodide is plotted versus temperature in Figure 2. Partial pressure (and therefore mole ratios) were subsequently determined by comparing the number of moles of methyl iodide to the sum of the number of moles of an ideal gas $(0.044 \mathrm{~mol} / \mathrm{l})$ and the number of moles of methyl iodide (resulting in a ppmv value when divided by $10^{6}$ ). 


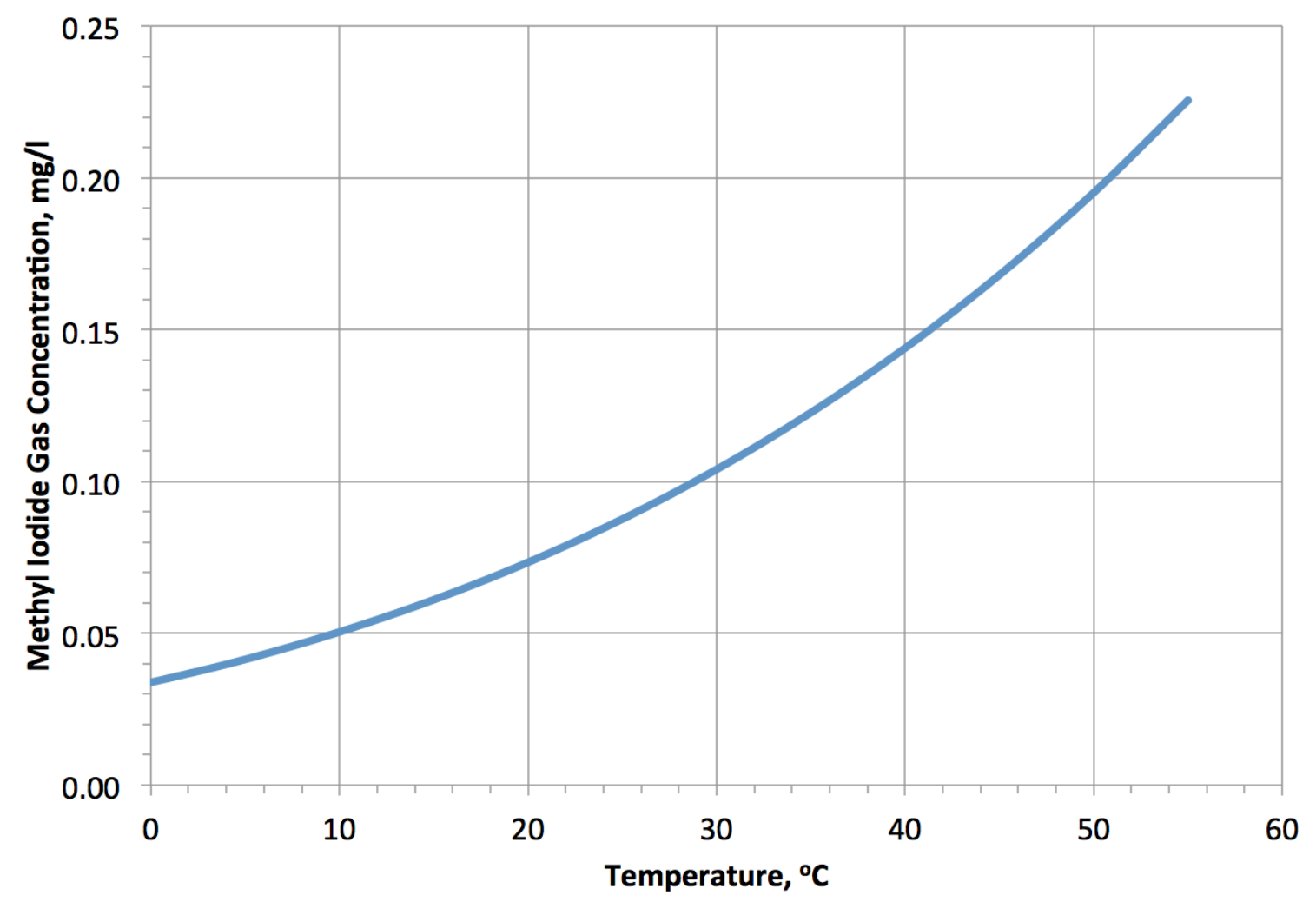

Figure 2. Theoretical concentration of methyl iodide in the gas phase at temperatures from 0 to $55^{\circ} \mathrm{C}$.

Fumigation of biological indicator ribbons ( $3 \times 10^{6}$ spores, 304 stainless steel) was performed in $48 \mathrm{ml}$ pressure-rated vessels, as detailed above. Several control samples were evaluated during each test, including vessels containing water and others vessels containing no liquid to study the relative effect of relative humidity and hot air respectively on spore death without methyl iodide.

Fumigation of $1 \times 10^{6}$ spores on concrete coupons was performed in $100 \mathrm{ml}$ pressure-rated vessels with a wider opening, as described above, with spores spiked onto concrete coupons.

\section{Recovery of Viable CFUs:}

Strict septic techniques were used during all of the procedural steps involving sample handling and dilutions. Stainless steel biological indicator ribbons were placed into individual sterile tubes containing $10 \mathrm{ml}$ of sterile distilled water. The carriers were soaked for 1 hour. Using sterile forceps, the biological indicator strip was bent into a coil such that the spores were on the inside edge at the end of the coil (this had previously facilitated placement in the pressure vessel for methyl iodide fumigation). Sonication of the biological indicators was performed in glass tubes for 1 hour. 
Dilution of the subsequent liquid following sonication was performed. $1 \mathrm{ml}$ of the $10 \mathrm{ml}$ solution was plated as the $10^{5} \mathrm{CFU} /$ plate fraction, $100 \mu \mathrm{l}$ as the $10^{4}$ fraction, and $10 \mu \mathrm{l}$ as the $10^{3}$ fraction and $1 \mu \mathrm{l}$ as the $10^{2}$ faction. The remaining liquid (nominally $8.889 \mathrm{ml}$ ) was filtered through a $0.45 \mu \mathrm{m}$ filter and plated as the $10^{6}$ $\mathrm{CFU} /$ plate fraction. The aliquots were spread directly onto tryptic soy agar (TSA) plates and incubated overnight at $30^{\circ} \mathrm{C}$.

Analysis of Viable CFUs:

B. anthracis colonies on the TSA plates were counted manually by visual inspection after 16 hours of incubation at $30^{\circ} \mathrm{C}$. The colony counts were multiplied by the dilution factor to give the total number of colony forming units for each biological indicator. If $1 \mathrm{ml}$ of the total $10 \mathrm{ml}$ (or 1/10) of the distilled water that the biological indicator was soaked and sonicated in was plated and yielded x number of colonies, then $\mathrm{x}$ was multiplied by 10 (the dilution factor) to give total number of colonies per biological indicator ribbon.

\section{Measuring Fumigation Efficacy:}

The efficacy of fumigation (and of the control samples) was then calculated and expressed as a "log-reduction" value by comparing the average number (bar) of viable CFUs before the experiment (non-exposed controls, $\mathrm{CFU}_{\mathrm{c}}$ ) and the average number of viable CFUs measured after fumigation $\left(\mathrm{CFU}_{\mathrm{f}}\right)$, as follows:

$$
\text { Efficacy }=\overline{\log _{10} C F U_{c}}-\overline{\log _{10} C F U_{f}}
$$

\section{Experimental Lessons Learned:}

Throughout this scoping study, lessons were learned about the behavior of methyl iodide gas and the fumigation of B. anthracis spores on both non-porous and porous materials.

The work was performed in a Class II B2 biosafety cabinet that provided protection from spores and HEPA-filtered exhaust to outside the building to vent methyl iodide vapors. Viton gloves were used when handling methyl iodide. The work required approval by both the LLNL Environmental Safety and Health (ES\&H) and the LLNL Institutional Biosafety Committee.

Pressure vessels were wrapped in aluminum foil to prevent photo-degradation of the light-sensitive methyl iodide during the experiment. 
Methyl iodide was found to penetrate or bind to PTFE sample stage, screw cap or glassware even after rinsing with water and autoclaving. Consequently, a certain number of experimental testing vessels and stages were designated for methyl iodide use only, while other vessels and stages were designated for control use only.

The recommended method for removal of spores from surfaces (which was successful for stainless steel biological indicators) was not appropriate for porous construction material such as concrete. The method produced fine particles in solution that had sloughed off the sample and spores adhered to the particles rather than being in solution prior to analysis. No failure was observed in the pressurerated glassware or 0-ring seals under the methyl iodide concentrations, temperatures and exposure times evaluated.

In most cases when 6-log efficacy was achieved, zero spores remained. To allow the calculation of a log-efficacy using the equation above, it was assumed in these cases that one spore remained on the surface.

\section{Results and Discussion}

Two temperatures were chosen for fumigation of spores, namely $55^{\circ} \mathrm{C}(\mathrm{a}$ temperature significantly above the boiling point of methyl iodide, $42.4^{\circ} \mathrm{C}$ ), and room temperature (below the methyl iodide boiling point). The higher temperature fumigation studies provided for higher concentrations of methyl iodide in the gas phase to partake in the fumigation of spores. Higher temperatures such as $55^{\circ} \mathrm{C}$ $\left(131^{\circ} \mathrm{F}\right)$ would be difficult to achieve for large buildings and may only be practical for small items that can be placed inside heated chambers. However, it is important to note that for military equipment such as planes and vehicles are likely to withstand such elevated temperatures, suggesting that rapid fumigation could be achieved. Room temperature fumigation (nominally 67 to $70^{\circ} \mathrm{F}$, or 19.4 to $21.1^{\circ} \mathrm{C}$ ) is more analogous to agricultural fumigation where methyl bromide and methyl iodide are applied to soil that is subsequently tented to minimize evaporation (or at least encourage condensation and reflux of the methyl iodide). Our experiments began with higher-temperature longer-time exposures since failure to kill spores with these conditions would indicate lower temperatures and shorter times would not be feasible.

Initial experiments with biological indicator ribbons suggested carry-over of methyl iodide in/on the PTFE sample stage (or the steel rod in the middle of the outer PTFE rod). Control samples in both water and air subsequently utilized designated tubes and stages that had not been exposed to methyl iodide. To remove the effect of methyl iodide carry-over effects, the PTFE sample stage and rod was replaced with fishing wire attached to the screw cap below the 0-ring. All equipment was autoclaved before each use. 
Elevated temperature and room temperature exposures of spores to methyl iodide are discussed below.

\section{Elevated Temperature Fumigation}

The effects of varying the exposure time at elevated temperature $\left(55^{\circ} \mathrm{C}\right)$ on the efficacy of methyl iodide fumigation are shown in Figure 3. Experiments were performed in duplicate and in reverse order, such that 24 hours was the first experiment that was performed. A 6-log kill of B. anthracis Sterne spores was achieved after just 1 hour at this elevated temperature. This exposure corresponds to a methyl iodide fumigation of $0.346 \mathrm{mg}$.hr/l (or $36.1 \mathrm{ppmv}-\mathbf{h r}$ ). The results for higher exposure times confirm 6-log efficacy is maintained, with the exception of data points at 4 and 12 hours, both of which had a large scatter in efficacy that ranged from $>6 \log$ to $>4 \log$. It is believed that this effect was due to anomalous experimental conditions since replicates showed expected higher efficacy - these two data points should be considered outliers, but are included here for completeness.

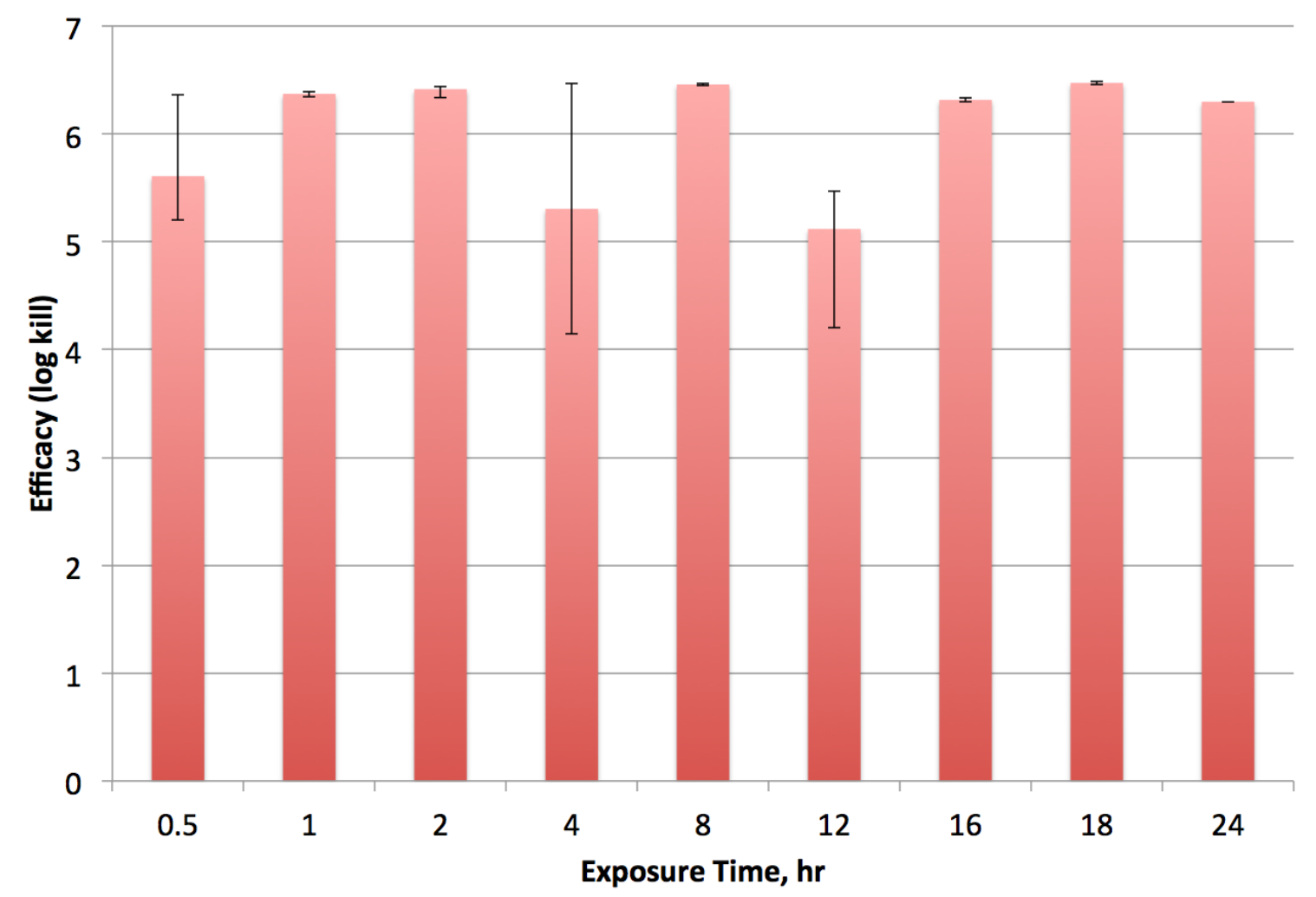

Figure 3. Efficacy of methyl iodide fumigation on B. anthracis Sterne strain spores $\left(3 \times 10^{6}\right)$ at room temperature $\left(55^{\circ} \mathrm{C}\right)$ 


\section{Room Temperature Fumigation}

The results of a range of exposure times at room temperature are shown in Figure 4. The fumigation efficacy at room temperature demonstrates time dependence as expected, with a 6-log kill of B. anthracis Sterne spores achieved after 12 hours at room temperature. According to the calculated methyl iodide concentration at $20^{\circ} \mathrm{C}$ in the vapor phase $(0.113 \mathrm{mg} / \mathrm{l}$, Figure 2$)$, the spores exposed at room temperature for 12 hours were subject to $1.356 \mathrm{mg} . \mathrm{hr} / \mathrm{l}$ (or $\mathbf{1 4 0 . 8} \mathbf{~ p p m v - h r}$ ) methyl iodide.

When compared to the exposures at elevated temperature, the efficacy is (not surprisingly) not as good at room temperature. Analysis of the water and air controls at elevated temperature show that the increased efficacy at higher temperature is not due to heat-shock of the spores, and as such the increase in efficacy gained by using elevated temperature is due to the increased concentration of methyl iodide in the gas phase.

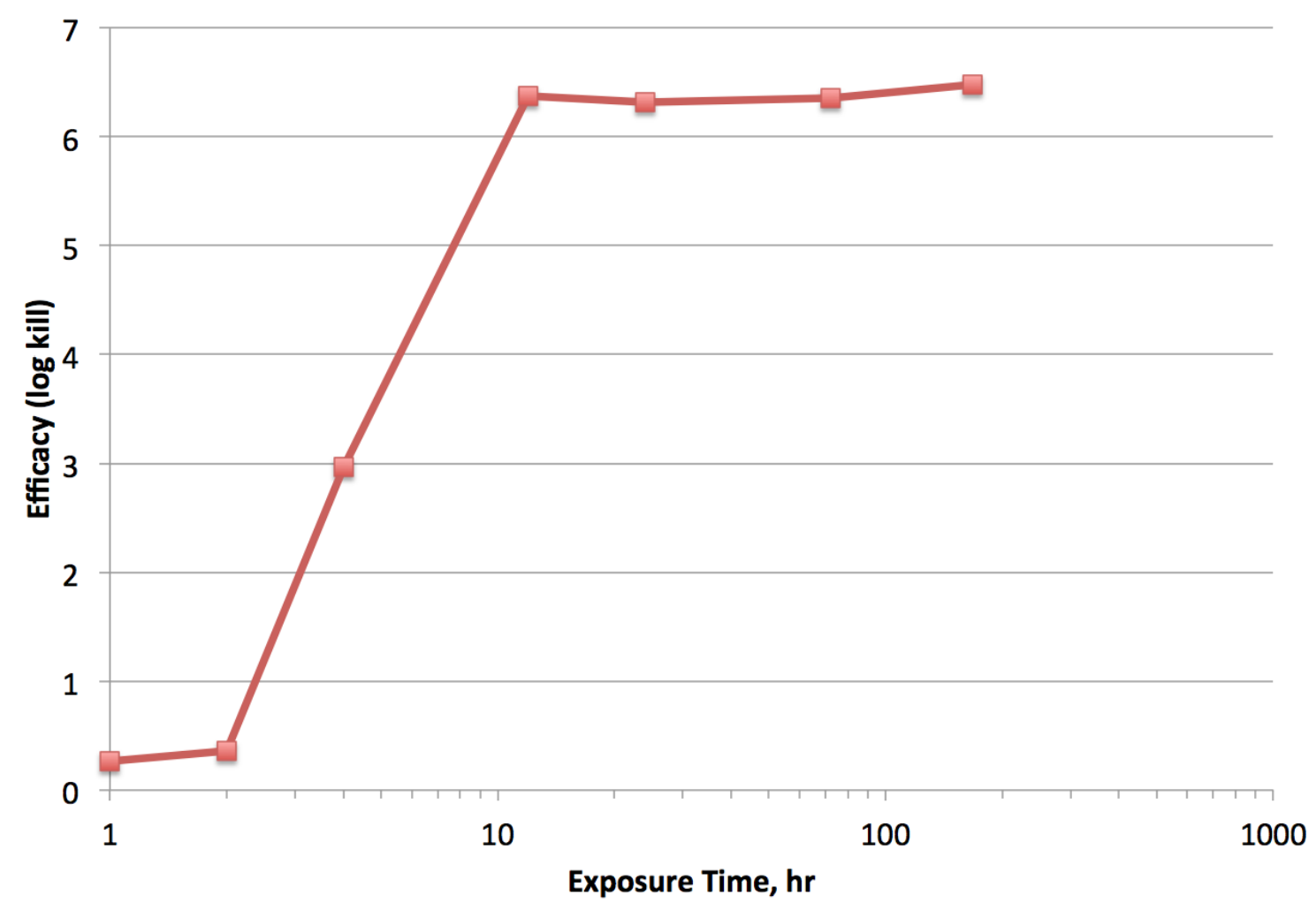

Figure 4. Efficacy of methyl iodide fumigation on B. anthracis Sterne strain spores $\left(3 \times 10^{6}\right)$ at room temperature (nominally $19-21^{\circ} \mathrm{C}$ )

Clearly, using higher temperatures (increasing the concentration of methyl iodide in the gas phase) results in much shorter exposure times required to obtain a reduction of $B$. anthracis spores by at least six orders of magnitude. This suggests that methyl iodide could allow efficient and rapid decontamination of military 
vehicles that can adequately withstand higher temperatures. For facilities, higher temperatures are difficult to both achieve and maintain, particularly in the case of building or room fumigation. Ambient room temperature is (by definition) easier to obtain and maintain, and since the contents are typically housed at room temperature, there is no heating concern with regard to materials. Therefore, for facilities we recommend using lower temperatures (e.g. room temperature) when 12 hours of fumigation is acceptable to schedule and resources.

Compared to methyl bromide tests performed by the EPA [EPA 2010] in which room temperature $\mathrm{MeBr}$ fumigation at $25^{\circ} \mathrm{C}$ for 9 hours at $211 \mathrm{ppmv}$ did not meet a 6-log kill efficacy standard for $\mathrm{B}$. anthracis spores $\left(18\right.$ hours at $37^{\circ} \mathrm{C}$ was required to achieve a 6-log kill), methyl iodide achieved a 6-log kill efficacy standard at lower temperature and with a lower concentration.

\section{Fumigation of Porous Surfaces}

The fumigation of B. anthracis spores on concrete was performed to assess the efficacy of methyl iodide on porous surfaces. Exposures of 2 hours and 4 hours at $55^{\circ} \mathrm{C}$ were performed. When compared to the initial number of CFUs applied to the concrete surface, a 2-hour exposure to methyl iodide resulted in an efficacy of 2.6, while the 4-hour exposure resulted in an efficacy of 5.1. These are lower efficacies than those observed for spores on stainless steel. Results from positive controls indicate that recovery of spores during the sonication and analysis stages of the experiment and significantly less than $100 \%$. This may be in part due to sorption of the spores on the fine particles of concrete that are removed from the bulk material during sonication prior to analysis. This observation requires additional investigation to both confirm assumptions and improve recovery. However, it is clear that a reduction in viable CFUs on the surface of concrete is observed due to methyl iodide fumigation. Further experiments should also investigate the chemical/structural effects of methyl iodide on porous surfaces, and any subsequent residual methyl iodide in/on porous surfaces after exposure.

\section{Conclusions}

The scoping study described in this report clearly shows that methyl iodide is an efficient sporicide in the neutralization of B. anthracis Sterne spores in the presence of both non-porous and porous materials. Efficacy was measured on a log scale and 6-log spore kill was observed after 1 hour at $55^{\circ} \mathrm{C}$ and after 12 hours at room temperature, making methyl iodide a viable (and potentially less detrimental) alternative to current fumigation techniques such as chlorine dioxide, vaporous hydrogen peroxide and paraformaldehyde. 
Recommended follow-on studies include examination of efficacy in the presence of organic materials, and evaluation of the effect of methyl iodide on simple electronic equipment such as a calculator and hard-drive, and on valuable materials such as paper documents. Additional analytical validation is needed for the recovery and analysis of spores from porous materials (such as concrete) whose surfaces may slough during sonication.

\section{Acknowledgements}

The authors greatly appreciate the financial support and oversight of Ryan Madden and colleagues at the Defense Threat Reduction Agency (DTRA).

\section{References}

Canter (2005) "Remediation of Bacillus anthracis Contamination in the U.S. Department of Justice Mail Facility" Canter, D. A. , Gunning, D., Rogers, P., O'Connor, L., Traunero, C. and Kempter, C. J. Biosecurity and Bioterrorism: Biodefense Strategy, Practice and Science, 2005; 3(2): 119-127

Canter (2010) personal communication, Dorothy Canter

CDC, Centers for Disease Control and Prevention, NIOSH Pocket Guide to Chemical Hazards, NIOSH 2005-149, available at http://www.cdc.gov/niosh/npg/

CDC (2009), Centers for Disease Control and Prevention, Anthrax Sterne strain (34F2) of Bacillus anthracis, available at http://www.cdc.gov/nczved/divisions/dfbmd/diseases/anthrax_sterne/

Corsi (2007), "Methyl Bromide as a Building Disinfectant: Interaction with Indoor Materials and Resulting Byproduct Formation" Corsi, R. L., Walker M. B., Lilgestrand, H. M., Hubbard, H. F., and Poppendieck, D. G. Journal of Air and Waste Management Association, 2007; 57: 576-585

CRC (2011), CRC Handbook of Chemistry and Physics, 92nd ed, 2011-2012, available at http://www.hbcpnetbase.com

DHHS (2005), U.S. Department of Health and Human Services, Report on Carcinogens, 11th Ed., Public Health Service, National Toxicology Program, available at http://ntp.niehs.nih.gov/index.cfm?objectid=32BA9724-F1F6-975E7FCE50709CB4C932

EPA (1999), U.S. Environmental Protection Agency, Alternative Disinfectants and Oxidants Guidance Manual, EPA/815/R-99/014 
EPA (2005), U.S. Environmental Protection Agency, Compilation of Available Data on Building Decontamination Alternatives, EPA/600/R-05/036, available at http://www.epa.gov/nhsrc/pubs/600r05036.pdf

EPA (2007), U.S. Environmental Protection Agency, Pesticide Fact Sheet: Iodomethane, available at www.epa.gov/opprd001/factsheets/iodomethane.pdf

EPA (2010), U.S. Environmental Protection Agency, Determining the Efficacy of Liquids and Fumigants in Systematic Decontamination Studies for Bacillus anthracis Using Multiple Test Methods, EPA/600/R-10/088, available at http://cfpub.epa.gov/si/si_public_file_download.cfm?p_download_id=500550

Juergensmeyer (2007), "Methyl Bromide Fumigant Lethal to Bacillus anthracis Spores" Juergensmeyer, M. A., Gingras, B. A., Scheffrahn, R. H. and Weinberg, M. J. Journal of Environmental Health 2007; 69(6): 24-26

Kolb (1950) "The Germicidal and Sporicidal Efficacy of Methyl Bromide for Bacillus Anthracis" Kolb R. W. and Schneiter R. J Bacteriol. 1950; 59(3): 401-412

Lorenz (1976) "Behavior of Iodine, Methyl Iodide, Cesium Oxide, and Cesium Iodide in Steam and Argon" Lorenz, R. A., Osborne, M. F., Collins, J. L., Manning, S. R. and Malinauskas, A. P. Oak Ridge National Laboratory Report ORNL/NUREG/TM-25, 1976

NRC (2005), National Research Council, Reopening Public Facilities after a Biological Attack, A Decision Framework, The National Academies Press

Ohr (1998) "Methyl Iodide, an Ozone-Safe Alternative to Methyl Bromide as a Soil Fumigant" Ohr, H. D., Sims, J. J., Grech, N. M., Becker, J. O. and McGiffen, M. E. Plant Disease 1998; 80(7): 731-735 